\title{
A TRAJETÓRIA DAS DIRETRIZES CURRICULARES NACIONAIS PARA A FORMAÇÃO DOCENTE NO BRASIL: UMA ANÁLISE DOS TEXTOS OFICIAIS
}

\author{
LA TRAYECTORIA DE LAS DIRETRIZES CURRICULARES NACIONALES PARA LA \\ FORMACIÓN DOCENTE EN BRASIL: ANALLISIS DE LOS TEXTOS OFICIALES
}

\author{
THE TRAJECTORY OF NATIONAL CURRICULUM GUIDELINES FOR TEACHING \\ TRAINING IN BRAZIL: AN ANALYSIS FROM OFFICIAL TEXTS
}

\author{
Gustavo Adolf FICHTER FILHO ${ }^{1}$ \\ Breynner Ricardo de OLIVEIRA ${ }^{2}$ \\ Jianne Ines Fialho COELHO ${ }^{3}$
}

RESUMO: O artigo analisa a trajetória das Diretrizes Curriculares Nacionais (DCN, 2002; 2015; 2019) no campo da formação docente no Brasil ao longo de um ciclo circunscrito por cinco governos (Fernando Henrique Cardoso, Luís Inácio Lula da Silva, Dilma Rousseff, Michel Temer e Jair Bolsonaro). Os documentos foram codificados a partir de quatro dimensões; (i) motivação e participação, (ii) diretrizes para temporalidade e estrutura dos cursos, (iii) profissionalidade docente e (iv) valorização profissional. Ao articular os textos oficiais ao longo de quase 20 anos, as análises reconstituem sua trajetória no campo da formação de professores, marcada por avanços, retrocessos e rupturas. Entre 2002 e 2015, as DCN enfatizam uma formação mais crítica, conjugando a formação inicial e a continuada, além da valorização profissional. O pós golpe de 2016 revela um agravamento do processo de desvalorização e enfraquecimento do status profissional da docência, manifesto nas DCN/2019.

PALAVRAS-CHAVE: Diretrizes Curriculares Nacionais. Formação docente. Políticas educacionais. Trajetória de políticas públicas.

RESUMEN: El artículo analiza la trayectoria de las Directrices Curriculares Nacionales (DCN, 2002; 2015; 2019) en el campo de la formación docente en Brasil a lo largo de un ciclo circunscrito por cinco gobiernos (Fernando Henrique Cardoso, Luís Inácio Lula da Silva, Dilma Rousseff, Michel Temer y Jair Bolsonaro). Los documentos fueron codificados en cuatro dimensiones; (i) motivación y participación, (ii) lineamientos para la temporalidad $y$ estructura de los cursos, (iii) profesionalismo docente y (iv) desarrollo profesional. Al articular los textos oficiales a lo largo de casi 20 años, los análisis reconstruyen su trayectoria en el campo de la formación docente, marcada por avances, retrocesos y rupturas. Entre 2002 y 2015, la DCN enfatiza la formación más crítica, combinando

\footnotetext{
${ }^{1}$ Universidade Federal de Ouro Preto (UFOP), Ouro Preto - MG - Brasil. Mestrando no Programa de PósGraduação em Educação. ORCID: https://orcid.org/0000-0002-5742-4264. E-mail: gustavofichterf@gmail.com ${ }^{2}$ Universidade Federal de Ouro Preto (UFOP), Ouro Preto - MG - Brasil. Professor no Programa de PósGraduação em Educação. Doutorado em Educação (UFMG). ORCID: https://orcid.org/0000-0003-0956-4753. E-mail: breynner.oliveira@gmail.com

${ }^{3}$ Universidade Federal de Ouro Preto (UFOP), Mariana - MG - Brasil. Doutoranda no Programa de PósGraduação em Educação. ORCID: https://orcid.org/0000-0003-0657-4649. E-mail: jiannecoelho@gmail.com
}

RIAEE - Revista Ibero-Americana de Estudos em Educação, Araraquara, v. 16, n. esp. 1, p. 940-956, mar. 2021. e-ISSN: 1982-5587 DOI: https://doi.org/10.21723/riaee.v16iEsp.1.14930 
formación inicial y continua, además del desarrollo profesional. El post-golpe de 2016 revela un agravamiento del proceso de devaluación y debilitamiento del estatus profesional de la docencia, manifestado en la DCN/2019.

PALABRAS CLAVE: Directrices Curriculares. Formación de profesores. Políticas educativas. Trayectoria de las políticas públicas.

ABSTRACT: The article analyzes the trajectory of the Diretrizes Curriculares Nacionais (DCN, 2002; 2015; 2019) in Brazil along a cycle circumscribed by five governments (Fernando Henrique Cardoso, Luís Inácio Lula da Silva, Dilma Rousseff, Michel Temer and Jair Bolsonaro). The documents were encoded based on four dimensions; (i) motivation and participation, (ii) guidelines for the temporality and structure of the courses, (iii) teaching professionalism and (iv) professional development. By articulating the official texts over almost 20 years, the analyzes reconstruct its trajectory in the field of teacher education, marked by advances, setbacks and ruptures. Between 2002 and 2015, the DCN emphasizes more critical training, combining initial and continuing training, in addition to professional development. The post-coup of 2016 reveals a worsening of the process of devaluation and weakening of the professional status of teaching, manifested in the DCN/2019.

KEYWORDS: National Curriculum Guidelines. Teacher education. Educational policies. Trajectory of public policies.

\section{Introdução}

Este artigo analisa a trajetória das Diretrizes Curriculares Nacionais (DCN, 2002; 2015; 2019) no campo da formação docente no Brasil ao longo de um ciclo circunscrito por cinco governos: Fernando Henrique Cardoso (1995-2003); Luís Inácio Lula da Silva (20032011); Dilma Rousseff (2011-2016); Michel Temer (2016-2019) e Jair Messias Bolsonaro (2019-2022). Segundo Diniz-Pereira (2016), as DCN para formação de professores foram elaboradas pelo Conselho Nacional de Educação (CNE) em resposta à regulamentação da Lei n. 9.394 de Diretrizes e Bases da Educação Nacional (LDBEN) (BRASIL, 1996). Em consonância com a Lei, as DCN definem os marcos curriculares e regulatórios para a formação docente, instituindo normas como carga horária e estruturação curricular das licenciaturas, além de questões como princípios formativos a serem considerados pelos cursos.

Segundo Oliveira (2019), as políticas têm trajetórias, e esse percurso não pode ser compreendido de maneira ordenada e linear. Segundo o autor, ao analisar as políticas incluindo as educacionais, há que se considerar seus avanços e retrocessos; como as concepções de diferentes governos moldam seus textos e como os interesses de atores envolvidos podem interferir em suas determinações. A trajetória das políticas é definida 
dinamicamente, à medida que as políticas navegam por diferentes governos, organizações e múltiplas arenas, movimentando-se em meio a processos sociais, políticos e econômicos, com seus sentidos, traduções e interpretações.

A análise das três DCN foi realizada com base nos pareceres e nas resoluções que as instituem: DCN/2002 (Parecer CNE/CP no. 9/2001; Resolução CNE/CP no. 1/2002; Resolução CNE/CP no. 2/2002); DCN/2015 (Parecer CNE/CP no. 2/2015; Resolução CNE/CP no. 2/2015); DCN/2019 (Parecer CNE/CP no. 22/2019; Resolução CNE/CP no. 2/2019). Os documentos foram codificados a partir de quatro dimensões; (i) motivação $e$ participação, (ii) diretrizes para temporalidade e estrutura dos cursos, (iii) profissionalidade docente e (iv) valorização profissional. Ao analisar a trajetória das diretrizes, compreendemos que os processos de elaboração e o conteúdo desses documentos fornecem evidências importantes sobre os diferentes paradigmas que influenciam a formação de professores no Brasil, ampliando a compreensão sobre esse campo.

A análise de textos, segundo Fairclough (2001), diz respeito a um procedimento desobrigado de neutralidade, tendo em vista que a leitura é permeada pelos referenciais - os descritores - de quem os codifica. No processo de leitura e análise das DCN, assim como nos estudos realizados por Costa (2016) e Shiroma, Campos e Garcia (2005), foram considerados os contextos políticos que envolvem a produção dos documentos, na busca pela compreensão das múltiplas concepções que regem essas diretrizes.

Assumimos que a compreensão do cenário de elaboração desses documentos e a maneira como são abordadas determinadas dimensões podem fornecer pistas sobre as concepções por trás da formulação dessas políticas e, por consequência, de suas trajetórias. Para o caso das DCN, a conjugação dos textos oficiais que organizam e estruturam esse campo revelam uma trajetória de quase 20 anos no campo da formação docente no Brasil. Tais documentos, marcados por diferentes concepções, parecem entrecruzar-se no tempo, o que pode produzir efeitos difusos nos cursos de licenciatura no país.

\section{As Diretrizes Curriculares Nacionais para Formação de Professores: 2002; 2015 e 2019}

Diniz-Pereira (2016) afirma que, em resposta à nova regulamentação da LDBEN, que delegou às Universidades a adequação de seus cursos às diretrizes cabíveis, o Conselho Nacional de Educação (CNE) e o Ministério da Educação (MEC) iniciaram, em 1997, um processo de elaboração de diretrizes curriculares para os cursos de graduação, contando com propostas de diferentes “organizações, entidades e instituições". Ainda segundo o autor, 
inicialmente as licenciaturas não receberam tratamento específico nesse processo, o que resultou na incorporação de diferentes concepções de formação às diretrizes de cada curso. Posteriormente, o MEC instituiu uma nova comissão responsável pela elaboração de diretrizes curriculares específicas para as licenciaturas, mas, dessa vez, sem a participação de entidades representativas.

Em 2001, no final do governo de Fernando Henrique Cardoso, o CNE publicou o parecer CNE/CP no. 09/2001, fruto da atividade de uma Comissão Bicameral do Conselho Nacional de Educação. O documento elencava um conjunto de diretrizes para a formação de professores da educação básica em nível superior. Amparado neste parecer, o CNE instituiu, por meio da resolução CNE/CP no. 01/2002 e da resolução CNE/CP no. 02/2002, respectivamente, as DCN para a formação de professores da Educação Básica e a carga horária dos cursos de licenciatura.

As DCN/2002, ao exigirem um processo de discussão e adequação das licenciaturas, representavam, pela primeira vez, uma possibilidade de superação do modelo de formação vigente no Brasil. Segundo Scheibe e Bazzo (2016), durante décadas, os cursos de formação de professores adotaram um modelo de priorização dos conteúdos específicos, no qual a formação se dava com um acréscimo de um ano de disciplinas do campo pedagógico após a efetivação de três anos de formação específica, modelo conhecido como " $3+1$ ". Os autores afirmam que essas DCN trouxeram uma nova perspectiva para a formação de professores, permitindo uma maior diversidade nos modelos de cursos. Ao sugerir uma reformulação do processo formativo de professores em todo o Brasil, foram ao encontro de uma demanda do campo educacional.

Apesar de acenarem uma possibilidade de avanço na formação de professores ao estabelecer diretrizes próprias para uma formação docente específica, as DCN/2002 não contemplaram todas as demandas das entidades e dos educadores, cedendo aos interesses das instituições privadas. Segundo Freitas (2002), trouxeram uma perspectiva de formação aligeirada, pautada no desenvolvimento de competências e habilidades. Ao longo de todo o documento, a questão do desenvolvimento de competências é tratada como ponto central da formação de professores.

As DCN/2002 instituíram 400 horas de prática como componente curricular. Com essa inovação, Diniz-Pereira (2016) afirma que a racionalidade prática passou a orientar a busca por novos modelos de formação de professores. Gatti et al. (2019) afirmam que, apesar das possibilidades abertas pelas DCN/2002, a maior parte das licenciaturas mantiveram suas 
estruturas curriculares, com a formação centrada nos conteúdos específicos de cada área de formação.

Em 2003, um novo ciclo político inicia-se no Brasil, com os governos de Luiz Inácio Lula da Silva (2003-2011) e Dilma Rousseff (2011-2016). Segundo Oliveira et al. (2018), esse novo período é marcado por grandes avanços nas políticas educacionais, incluindo os programas de formação inicial e continuada de professores, no âmbito do Plano Nacional de Educação (PNE 2014-2024), aprovado com 20 metas a serem alcançadas em 10 anos.

Em continuidade com as diversas políticas que marcam esse período, o CNE definiu, em 2015, novas Diretrizes Curriculares Nacionais para a formação de professores (DCN/2015) por meio da resolução CNE/CP no. 2 de 2015, amparada pelo parecer CNE/CP no. 1 de 2015, substituindo as DCN/2002. Segundo Gatti et al. (2019, p. 72.), esse documento “[...] evoca mudanças profundas nas instituições formadoras, nos currículos das licenciaturas e nas posturas dos formadores".

Por meio do decreto no. 8.752 de 2016, poucos dias antes do fim do governo Dilma e em consonância com a meta 15 do PNE, foi instituída a Política Nacional de Formação dos Profissionais da Educação Básica. Dourado (2016), afirma que essa nova política determinou, em um único documento, a política nacional para a formação de professores, pedagogos e demais profissionais da educação básica. Dessa forma, ao considerar as DCN/2015, além de outros documentos, como a Resolução CNE/CES no. 2/2016, que instituiu as DCN para formação de funcionários da educação básica, a Política Nacional de Formação articula a agenda no campo com mais organicidade.

Após o golpe parlamentar, em maio de 2016 o vice-presidente Michel Temer assume o a Presidência da República. Oliveira et al. (2018) afirmam que esse governo foi marcado por mudanças radicais para o país, impactando significativamente nas políticas de formação de professores. Um marco desse governo foi a Emenda Constitucional 95 de 2016, que congelou despesas dos três poderes até o ano de 2036. Esse Novo Regime Fiscal ameaça questões importantes para o desenvolvimento social brasileiro, incluindo as metas do PNE.

Em agosto de 2017, completado o prazo de dois anos para adequação das licenciaturas às $\mathrm{DCN} / 2015$, a resolução $\mathrm{CNE} / \mathrm{CP}$ 01/2017 adia em um ano esse período. Em dezembro do mesmo ano, o MEC anuncia uma nova Política Nacional de Formação de Professores, com o programa Residência Pedagógica e a ampliação de vagas na Universidade Aberta do Brasil (UAB) e no Programa Universidade Para Todos (PROUNI) para cursos de licenciatura. Entidades como a Associação Nacional de Pós-Graduação e Pesquisa (ANPEd) e a Associação Nacional pela Formação dos Profissionais da Educação (ANFOPE) se 
posicionaram contrárias à política, afirmando que sua elaboração foi feita sem o envolvimento de entidades e associações do campo educacional, e ignorando a necessidade de articulação entre formação inicial, continuada e valorização da profissão ${ }^{4}$.

Ainda nesse período, a resolução CNE/CP 02/2017, em processo conturbado e com críticas do campo educacional, institui a Base Nacional Comum Curricular (BNCC) da educação básica, retomando a ideia do desenvolvimento de competências e habilidades. Dourado e Siqueira (2019) afirmam que a aprovação da BNCC pelo CNE se deu de maneira "coercitiva e aligeirada", não sendo aprovada por unanimidade de seus membros. Em outubro de 2018, o Conselho Nacional de Educação, por meio da resolução CNE/CP 03/2018, adia em um ano o prazo para implementação das DCN/2015.

Em 2019, Jair Bolsonaro, do Partido Social Liberal, toma posse. No mesmo ano, o Parecer CNE/CP no. 22 embasa a instituição de novas DCN para formação de professores, por meio da resolução $\mathrm{CNE} / \mathrm{CP}$ no. 2 de 2019. Em menos de 20 anos, três diretrizes foram instituídas, revelando os avanços e as disputas no campo da formação de professores.

\section{A trajetória das DCN}

\section{Motivação e participação}

É importante compreender uma política em sua totalidade, desde a definição das agendas e da elaboração dos textos até os processos de implementação que dão materialidade às políticas. Dessa forma, a primeira dimensão refere-se ao processo de elaboração das DCN, abordando questões como motivação e participação. Buscamos compreender duas questões principais, sintetizadas no quadro 1: (1) as justificativas elencadas para a produção dessas diretrizes; (2) como os documentos revelam a participação das entidades e associações do campo da educação e da formação de professores no processo de elaboração.

Quadro 1 - Análise da dimensão motivação e participação

\begin{tabular}{|c|c|c|c|c|}
\hline Dimensão & Categorias & DCN 2002 & DCN 2015 & DCN 2019 \\
\hline \multirow{2}{*}{$\begin{array}{c}\text { Motivação e } \\
\text { participação }\end{array}$} & $\begin{array}{c}\text { Justificativa de } \\
\text { produção }\end{array}$ & $\begin{array}{c}\text { "preparo inadequado dos } \\
\text { professores" em "um formato } \\
\text { tradicional" }\end{array}$ & $\begin{array}{c}\text { busca por "maior organicidade das } \\
\text { políticas, programas e ações } \\
\text { atinentes à formação inicial e } \\
\text { continuada" }\end{array}$ & $\begin{array}{c}\text { busca por “adequação das } \\
\text { licenciaturas com a } \\
\text { BNCC" e suas } \\
\text { competências }\end{array}$ \\
\cline { 3 - 5 } & $\begin{array}{c}\text { "construir sintonia entre a } \\
\text { formação de professores", a } \\
\text { LDB e parâmetros e diretrizes }\end{array}$ & $\begin{array}{c}\text { "romper com as assimetrias } \\
\text { nacionais, regionais, estaduais, } \\
\text { municipais e institucionais" }\end{array}$ & $\begin{array}{c}\text { (Lei no. 13.415 de 16 de } \\
\text { fevereiro de 2017) }\end{array}$ \\
\hline
\end{tabular}

4 Manifestação das entidades educacionais sobre a política de formação de professores anunciada pelo MEC (20/10/2017). Disponível em: <www.anped.org.br/news/manifestacao-das-entidades-educacionais-sobrepolitica-de-formacao-de-professores-anunciada $>$. 


\begin{tabular}{|c|c|c|c|}
\hline & da educação básica & & \\
\hline & $\begin{array}{l}\text { "definição de currículos } \\
\text { próprios da Licenciatura" que } \\
\text { não se confundam com o } \\
\text { Bacharelado }\end{array}$ & $\begin{array}{l}\text { "garantir profissionais com } \\
\text { formação adequada nas diferentes } \\
\text { etapas e modalidades e propiciar } \\
\text { maior organicidade à formação" }\end{array}$ & $\begin{array}{c}\text { "melhoria da qualidade do } \\
\text { ensino e da aprendizagem } \\
\text { escolar" }\end{array}$ \\
\hline Participação de & $\begin{array}{l}\text { "longo processo de crítica, } \\
\text { reflexão e confronto entre } \\
\text { diferentes concepções sobre a } \\
\text { formação" }\end{array}$ & $\begin{array}{l}\text { assegurou "a participação da } \\
\text { sociedade" incorporando } \\
\text { "contribuições da audiência } \\
\text { pública". }\end{array}$ & $\begin{array}{c}\text { "uma série de reuniões [...] } \\
\text { com o objetivo de } \\
\text { apresentar e discutir a } \\
\text { proposta" }\end{array}$ \\
\hline educacional & $\begin{array}{c}\text { Cita diversas entidades e } \\
\text { associações como ANPEd, } \\
\text { Anfope, Consed, UNDIME, } \\
\text { dentre outras. }\end{array}$ & $\begin{array}{c}\text { Cita diversas entidades e } \\
\text { associações como ANPEd, } \\
\text { Anfope, Consed, UNDIME, dentre } \\
\text { outras. }\end{array}$ & $\begin{array}{l}\text { Afirma que foi realizada } \\
\text { "uma série de reuniões } \\
\text { com diferentes setores } \\
\text { da Educação brasileira". }\end{array}$ \\
\hline
\end{tabular}

Fonte: Elaborado pelos autores

Tanto o parecer que embasa as DCN/2002 quanto as DCN/2015 citam diversas entidades e associações (como a ANPEd, ANFOPE, ANPAE, CONSED, UNDIME5 ${ }^{5}$ ) envolvidas no processo de elaboração das diretrizes, em audiências, reuniões e outros espaços de críticas e discussões. Apesar disso, Freitas (2002) afirma que que as DCN/2002 não foram ao encontro das demandas do campo. Da mesma forma, Diniz-Pereira (2016) afirma que o tratamento dado às contribuições dessas entidades foi diminuto quando comparado às diretrizes dos bacharelados. Ambas as diretrizes, novamente, citam a importância do debate: o parecer CNE/CP 09/2001 cita o "processo de crítica, reflexão e confronto entre diferentes concepções"; enquanto o parecer CNE/CP 01/2015 cita a incorporação das contribuições da audiência pública e também de outros documentos e sugestões recebidas.

O parecer de CNE/CP 22/2019, por outro lado, apesar de citar uma série de reuniões com setores da Educação brasileira, não especifica nomes de entidades e associações envolvidas. Em outubro de 2019, diversas entidades nacionais do campo da educação assinaram uma nota se posicionando contrariamente às novas DCN/2015, caracterizando a proposta colocada até o momento como "danosa à elevação da qualidade da educação brasileira" e um "franco desrespeito às instituições, professores e estudantes" ". No que diz respeito às justificativas de elaboração apresentadas nos pareceres que embasam as DCN, todos os documentos apresentam justificativas relacionadas à qualidade da formação dos professores e à garantia de qualidade da educação básica.

As DCN de 2002 surgem como as primeiras para as Licenciaturas. Segundo Gatti et al. (2019), o estabelecimento dessas diretrizes em 2002 é de suma importância, uma vez que o campo da formação de professores no Brasil carecia de políticas estruturadas, voltadas para as

\footnotetext{
5 ANPAE - Associação Nacional de Política e Administração da Educação; CONSED - Conselho Nacional de Secretários de Educação; UNDIME - União Nacional dos Dirigentes Municipais de Educação.

6 Disponível em: https://anped.org.br/sites/default/files/images/nota_entidades_bncf_outubro2019.pdf. Acesso em: 10 set. 2020.
} 
especificidades da formação docente. Da mesma forma, àquela época, a publicação de diretrizes representava uma possibilidade de superação dos modelos de formação, há muito tempo problematizados (SCHEIBE; BAZZO, 2016).

As DCN/2015, por outro lado, foram publicadas após longo debate nacional, articulado pelo CNE. O parecer cita a Comissão Bicameral do CNE para estudos de formação de professores com várias recomposições entre 2004 e 2014, o que é coerente com a afirmação de Dourado (2016) sobre o estabelecimento dessas discussões desde 2004, com o envolvimento de diversas associações, instituições e entidades do campo da formação de professores. Dessa forma, o processo de discussão dessas diretrizes, iniciado apenas dois anos após a publicação das anteriores, revela que, de fato, a formação de professores constitui-se como um campo de embates e disputas de concepções.

O parecer também apresenta o argumento da busca por organicidade entre demais políticas de formação, coerente com o período de 2003-2015, em que diversas políticas para a formação foram desenvolvidas e implementadas. Além disso, argumenta a necessidade de se romper com as assimetrias nacionais, regionais, estaduais, municipais e institucionais.

Como é evidente no parecer de 2019, as DCN têm a intenção clara de buscar coerência entre a BNCC e a formação docente. Também é expressa a preocupação com o de desenvolvimento de competências nas licenciaturas, característica que estava presente nas DCN/2002 e havia sido superada nas DCN/2015.

O período de discussão dessas últimas diretrizes é mais curto que o das anteriores, entre 2017 e 2019. Esse período traz indicativos que as resoluções CNE/CP 01/2017 e CNE/CP 03/2018, que adiaram o prazo de adequação das Licenciaturas às DCN/2015, já sinalizavam esforços para substituí-las. Esse pequeno período de discussão também é coerente com a afirmação de Dourado e Siqueira (2019) que, ao tratar da aprovação da BNCC, afirma que seu processo de discussão e aprovação ocorreu de maneira "coercitiva e aligeirada". Além disso, a preocupação expressa por Dourado e Siqueira (2019) indica que as novas diretrizes podem não ter sido pensadas em profundidade, em diálogo com mais atores, entidades, instituições e associações interessadas, como foi nas DCN/2015.

\section{Carga horária e organização curricular dos cursos}

A segunda dimensão diz respeito ao que as diretrizes determinam em relação à carga horária dos cursos de licenciatura e sua organização curricular. Comparamos três categorias: a 
carga horária de formação, o tempo mínimo para sua efetivação e como essa carga horária deve ser distribuída na estrutura dos cursos, conforme disposto no quadro 2.

Quadro 2 - Análise da dimensão diretrizes para temporalidade e estrutura dos cursos

\begin{tabular}{|c|c|c|c|}
\hline Categorias & DCN/2002 & DCN/2015 & DCN/2019 \\
\hline $\begin{array}{l}\text { Carga horária de } \\
\text { formação }\end{array}$ & Mínimo de 2800 horas totais & Mínimo de 3200 horas totais & Mínimo de 3200 horas totais \\
\hline Tempo de efetivação & Mínimo de 3 anos de curso & Mínimo de 4 anos ou 8 períodos & Não especificado \\
\hline Estruturação curricular & $\begin{array}{l}400 \text { horas de prática como } \\
\text { componente curricular; } \\
400 \text { horas de estágio curricular } \\
\text { supervisionado; } \\
1800 \text { horas para conteúdos de } \\
\text { natureza científico cultural; } \\
200 \text { horas para outras formas de } \\
\text { atividades acadêmico-científico- } \\
\text { culturais. }\end{array}$ & $\begin{array}{l}400 \text { horas de prática como } \\
\text { componente curricular; } \\
400 \text { horas de estágio; } \\
2200 \text { horas de atividades } \\
\text { formativas dos núcleos I e II; } \\
200 \text { horas para outras atividades de } \\
\text { interesse do estudante (núcleo III). }\end{array}$ & $\begin{array}{l}800 \text { horas para conhecimentos } \\
\text { científicos, educacionais e } \\
\text { pedagógicos; } \\
1600 \text { horas para conteúdos } \\
\text { específicos das áreas; } \\
800 \text { horas de prática pedagógica, } \\
\text { divididas em } 400 \text { horas de estágio e } \\
400 \text { horas de prática dos } \\
\text { componentes curriculares. }\end{array}$ \\
\hline
\end{tabular}

Fonte: Elaborado pelos autores

As diretrizes de 2015 e 2019 avançaram em relação às de 2002, ao aumentarem a carga horária mínima de 2.800 para 3.200 horas. Esse movimento condiz com uma expectativa de uma formação teórica e prática robusta para a formação de professores. Nas primeiras DCN, conforme Freitas (2002), o estabelecimento de 2.800 horas se deu em função de pressões do setor privado.

O tempo mínimo para efetivação dessa carga horária evidencia, no entanto, um movimento em ziguezague. Em 2002, as diretrizes instituíram um mínimo de três anos de curso para efetivação das 2.800 horas de formação. Ao passo que essa carga horária foi aumentada pelas DCN/2015, o tempo mínimo para efetivação do curso também aumentou para quatro anos ou oito períodos letivos. Em 2019, por outro lado, o tempo mínimo para efetivação do curso foi removido. Este fato é visto com preocupação, uma vez que práticas formativas aligeiradas podem ser referendadas pela não existência de um tempo mínimo.

Sobre a distribuição dessa carga horária nas licenciaturas, evidenciamos alguns padrões. Em todas elas as 400 horas de prática como componente curricular e as 400 horas de estágio curricular supervisionado são mantidas. As 200 horas para outras atividades de formação estão presentes nas DCN de 2002 e 2015, com a consideração do interesse do estudante nas diretrizes de 2015. As DCN/2019 não instituem essa carga-horária.

As diretrizes de 2002 determinam que as 1.800 horas restantes sejam destinadas à conteúdos de natureza científico cultural. As diretrizes de 2015 determinam 2.200 horas para as atividades formativas dos núcleos I e II, descritos, respectivamente, como núcleos de "estudos de formação geral, das áreas específicas e interdisciplinares, e do campo educacional" e de "aprofundamento e diversificação de estudos das áreas de atuação 
profissional, incluindo os conteúdos específicos e pedagógicos". As diretrizes de 2019, por outro lado, são mais objetivas ao determinar 800 horas para conhecimentos educacionais e 1600 horas para conteúdos específicos, priorizando, portanto, o campo de conhecimento específico de cada licenciatura.

\section{Profissionalidade docente}

A decisão a respeito de como formar professores envolve a compreensão sobre $o$ que são professores ou sobre o que se espera que eles sejam. Roldão (2005) fornece quatro descritores que buscam explicar a profissionalidade docente - características que descrevem e distinguem a profissão docente das demais. A terceira dimensão estrutura-se em quatro categorias: a especificidade da função, ou a atividade específica exercida pela profissão; os saberes específicos necessários para sua atividade; a autonomia, ou o poder de decisão; e a pertença à um coletivo, que regula e defende a profissão, conforme disposto no quadro 3.

\section{Quadro 3 - Análise da dimensão Profissionalidade Docente}

\begin{tabular}{|c|c|c|c|}
\hline Categorias & DCN/2002 & DCN/2015 & DCN/2019 \\
\hline \multirow{3}{*}{ Especificidade da função } & \multirow{3}{*}{ "cuidar da aprendizagem" } & "atuam diretamente no ensino" & "zelo pela aprendizagem" \\
\hline & & "agentes formativos de cultura" & $\begin{array}{c}\text { "formativos de conhecimento e } \\
\text { cultura" }\end{array}$ \\
\hline & & $\begin{array}{l}\text { "práxis como expressão da } \\
\text { articulação entre teoria e prática" }\end{array}$ & $\begin{array}{l}\text { "desenvolver competências } \\
\text { socioemocionais em seus } \\
\text { estudantes" }\end{array}$ \\
\hline \multirow{4}{*}{ Saberes específicos } & \multirow[t]{2}{*}{ competências } & $\begin{array}{l}\text { conhecimentos "específicos, } \\
\text { interdisciplinares e pedagógicos" e } \\
\text { "científicos e culturais" }\end{array}$ & \multirow[t]{2}{*}{ competências } \\
\hline & & "valores éticos, políticos" & \\
\hline & "conhecimentos específicos" & $\begin{array}{l}\text { "acesso permanente a informações, } \\
\text { vivência e atualização culturais" }\end{array}$ & \multirow{2}{*}{$\begin{array}{l}\text { "acesso permanente a informações, } \\
\text { vivência e atualização culturais" }\end{array}$} \\
\hline & $\begin{array}{l}\text { "compreensão das questões } \\
\text { envolvidas em seu trabalho" }\end{array}$ & $\begin{array}{l}\text { "resultado do projeto pedagógico e } \\
\text { do percurso formativo vivenciado" }\end{array}$ & \\
\hline \multirow{2}{*}{ Autonomia } & \multirow{2}{*}{$\begin{array}{c}\text { "autonomia para tomar decisões, } \\
\text { responsabilidade pelas opções } \\
\text { feitas" }\end{array}$} & \multirow{2}{*}{$\begin{array}{l}\text { autonomia possibilitada pela } \\
\text { formação }\end{array}$} & $\begin{array}{l}\text { Fundamento pedagógico da } \\
\text { formação }\end{array}$ \\
\hline & & & $\begin{array}{l}\text { Autonomia com seu "próprio } \\
\text { desenvolvimento profissional" }\end{array}$ \\
\hline \multirow{3}{*}{ Coletivo } & \multirow{3}{*}{$\begin{array}{l}\text { "interagir cooperativamente com a } \\
\text { comunidade profissional" }\end{array}$} & \multirow{2}{*}{$\begin{array}{l}\text { trabalho coletivo possibilitado pela } \\
\text { formação }\end{array}$} & $\begin{array}{c}\text { "trabalhar coletivamente" como uma } \\
\text { competência }\end{array}$ \\
\hline & & & \multirow{2}{*}{$\begin{array}{l}\text { "participar das comunidades de } \\
\text { aprendizagem" como uma } \\
\text { competência }\end{array}$} \\
\hline & & $\begin{array}{l}\text { "construção, definição coletiva" dos } \\
\text { planos de carreira }\end{array}$ & \\
\hline
\end{tabular}

Fonte: Elaborado pelos autores

As DCN/2002 informam que a principal tarefa do docente é cuidar da aprendizagem dos alunos. As diretrizes de 2015, por outro lado, ampliam essa tarefa ao afirmar que, mediante a atuação no ensino, os professores agem como agentes formativos de cultura. Por 
sua vez, as DCN/2019 retomam ambas as definições, afirmando tanto o zelo pela aprendizagem, como a formação de conhecimento e cultura, adicionando também, em sua definição sobre especificidade do trabalho docente, a função do desenvolvimento das competências socioemocionais de seus alunos.

Ao buscar identificar menções que tratam de saberes que devem embasar a formação dos professores (ou que devem embasar a atuação desses profissionais), encontramos referências a conhecimentos específicos, pedagógicos ou interdisciplinares, presentes nas três diretrizes. As DCN de 2015 e 2019, no entanto, destacam a necessidade de acesso permanente a informações, vivências e atualizações culturais. Essa referência condiz com a análise de Tardif (2000), que descreve como uma das características dos saberes docentes seu desenvolvimento através do tempo. As diretrizes de 2015 atestam essa temporalidade dos saberes docentes ao afirmar que a consolidação dos conhecimentos dos professores virá através do seu exercício profissional.

Todas as diretrizes fazem referências à autonomia. Entretanto, elas não aprofundam em suas compreensões sobre ela. As DCN/2002 a associam à responsabilidade pelas decisões feitas. As DCN de 2015 e 2019, por sua vez, citam a necessidade de que ela seja desenvolvida pela formação.

Em relação à categoria pertença ao coletivo, as diretrizes trazem referências simples à essa categoria, geralmente abordando o trabalho coletivo, mas sem detalhes maiores. As DCN de 2002 abordam que o professor precisa interagir cooperativamente com a comunidade profissional, ao passo que as competências propostas pelas diretrizes de 2019 incluem a dimensão engajamento profissional. No entanto, as diretrizes de 2015 abordam a necessidade de construção e definição coletiva dos planos de carreira.

\section{Valorização profissional}

Segundo Nóvoa (2017), as reformas educacionais de cunho neoliberal intensificaram um processo de precarização das condições de trabalho - que dizem respeito à uma desvalorização material da docência - e de disseminação de discursos que negam a importância ou propõem o aligeiramento da formação docente - um processo de desvalorização simbólica. Dessa forma, essas duas categorias - valorização material e valorização simbólica - constituem a dimensão valorização profissional de nossa análise, disposta no quadro 4. 
Quadro 4 - Análise da dimensão Valorização Profissional

\begin{tabular}{|c|c|c|c|}
\hline Categorias & $\mathrm{DCN} / 2002$ & DCN/2015 & DCN/2019 \\
\hline Valorização Material & $\begin{array}{l}\text { depende de políticas que definam } \\
\text { "jornada de trabalho", "planos de } \\
\text { carreira" e "níveis de remuneração } \\
\text { condigna com a importância social } \\
\text { do trabalho" }\end{array}$ & $\begin{array}{l}\text { "a garantia de construção, } \\
\text { definição coletiva e aprovação de } \\
\text { planos de carreira e salário, com } \\
\text { condições que assegurem jornada } \\
\text { de trabalho com dedicação } \\
\text { exclusiva ou tempo integral a ser } \\
\text { cumprida em um único } \\
\text { estabelecimento de ensino e } \\
\text { destinação de } 1 / 3 \text { (um terço) da } \\
\text { carga horária de trabalho a outras } \\
\text { atividades pedagógicas inerentes } \\
\text { ao exercício do magistério" }\end{array}$ & $\begin{array}{l}\text { Retoma as metas } 17 \text { e } 18 \text { do PNE } \\
\text { que tratam da "equivalência } \\
\text { salarial" } \\
\text { profissionais" } \\
\text { carreira" }\end{array}$ \\
\hline \multirow{2}{*}{ Valorização Simbólica } & \multirow{2}{*}{$\begin{array}{l}\text { "práticas próprias da atividade } \\
\text { de professor e às múltiplas } \\
\text { competências que as compõem" } \\
\text { devem ser valorizadas }\end{array}$} & \multirow{2}{*}{$\begin{array}{l}\text { "concepção ampla e valorização } \\
\text { entendida a partir da articulação } \\
\text { entre formação inicial, formação } \\
\text { continuada, carreira, salários e } \\
\text { condições de trabalho" }\end{array}$} & \begin{tabular}{llcr} 
"associar a & \multicolumn{2}{c}{ valorização à } \\
formação" & para & garantir \\
atratividade da carreira & \\
\end{tabular} \\
\hline & & & $\begin{array}{l}\text { "Inclui o reconhecimento e o } \\
\text { fortalecimento dos saberes } \mathrm{e} \\
\text { práticas" }\end{array}$ \\
\hline
\end{tabular}

Fonte: Elaborado pelos autores

O parecer CNE/CP 02 de 2001 faz referências à valorização simbólica e material da profissão docente. $\mathrm{O}$ texto cita que as competências e as práticas próprias da atividade devem ser valorizadas. Em outro momento, o documento afirma que a qualificação profissional perpassa por políticas que visem definir planos de carreira e remuneração condigna com a importância social do trabalho. Entretanto, essas informações foram omitidas na estruturação das resoluções CNE/CP 01 e 02 de 2002, que instituem as diretrizes.

As DCN/2015 avançam ao evidenciar uma concepção sólida de valorização, presente tanto na resolução quanto no parecer. Nessa concepção, articulam questões materiais (salário, carreira, condições de trabalho) com questões simbólicas (formação inicial e continuada).

É importante ressaltar que a Resolução CNE/CP 02 de 2015 trata não somente de diretrizes para a formação inicial, mas também para a continuada, além de cursos de formação pedagógica e segunda licenciatura. Além disso, a valorização dos profissionais do magistério recebe atenção especial no capítulo VII da referida resolução. Esses argumentos atestam uma concepção sólida de articulação entre elementos formativos e de valorização material do magistério.

As diretrizes de 2019 citam a necessidade do reconhecimento e fortalecimento dos saberes e práticas docentes, e de articulação entre formação e valorização da profissão. Elas também retomam o PNE ao tratar da importância da equivalência salarial entre profissionais do magistério e outros profissionais com a mesma titulação. Apesar dessas ponderações, as diretrizes retrocedem ao remover a valorização docente como um dos eixos estruturantes das diretrizes, presente nas DCN/2015. 
Evidenciamos que as DCN/2015 trazem uma concepção mais sólida de valorização profissional, ao tratar de condições de trabalho, carreira, formação e valorização de maneira articulada. Essa perspectiva converge com diversos autores da área, como Diniz-Pereira (2016) e Nóvoa (2017), que pautam a necessidade de sua articulação. As DCN de 2019, ao remover essa concepção de seus textos, se articula com outros movimentos dos governos posteriores à 2016, que, assim como a autorização de profissionais com "notório saber", contribuíram para a desvalorização e desprofissionalização docentes.

\section{Considerações finais}

Neste artigo, discutimos a trajetória das DCN para formação de professores no Brasil, que se inicia com a instituição das primeiras diretrizes próprias para as licenciaturas, em 2002. A consolidação da obrigatoriedade da prática como componente curricular e dos estágios supervisionados sinalizaram a necessidade de materialização da especificidade dos cursos de formação de professores. Conforme Gatti et al. (2019), essas DCN marcaram um momento de possibilidades para a formação de professores. Segundo Freitas (2002), apesar desses avanços, essas diretrizes não dialogaram com demandas do campo. A centralização das competências, o reduzido tempo mínimo para efetivação do curso (três anos) e a redução da função docente ao cuidado com a aprendizagem, atestam uma concepção simplificada e tecnicista da docência, construída em uma formação aligeirada.

Os governos Lula e Dilma avançaram em direção à superação dessas perspectivas ao longo dos 14 anos de uma trajetória mais orgânica no campo. As DCN/2015 se fundamentaram em ideias mais críticas, compreendendo professores como sujeitos "formativos de conhecimento e cultura", com "valores éticos e políticos". Pautaram uma concepção de valorização profissional que articulou formação inicial e continuada com condições de trabalho e carreira, assim como defendido por autores como Diniz-Pereira (2015) e Nóvoa (2017). Além disso, aumentaram a carga horária (3.200 horas) e o tempo mínimo para efetivação dos cursos (quatro anos). A trajetória dessas políticas sinalizava um caminho à criticidade, autonomia e novas possibilidades para os cursos de licenciatura.

Essa trajetória não revela, entretanto, linearidade. O fim do governo Dilma, marcado por um golpe parlamentar (BASTOS, 2017), abriu espaço para um novo ciclo. Dourado e Siqueira (2019) compreendem uma "contrarreforma, bastante conservadora e privatista, no campo da educação" durante o governo Temer. As políticas que daí advieram agravaram o processo de desvalorização e enfraquecimento do status profissional da docência.

RIAEE - Revista Ibero-Americana de Estudos em Educação, Araraquara, v. 16, n. esp. 1, p. 940-956, mar. 2021. e-ISSN: 1982-5587 
As DCN/2019, já no governo Bolsonaro, parecem agravar esse ciclo políticoideológico. Retomando questões superadas pelas diretrizes de 2015, se reaproximaram das concepções vigentes em 2002, como a centralização da formação em competências, um esvaziamento crítico e a possibilidade de aligeiramento da formação, em decorrência da não especificação de um tempo mínimo para efetivação dos cursos. Outro significativo retrocesso diz respeito à remoção da ideia articulada de valorização profissional, além da redução da relevância dada à formação continuada.

Diniz-Pereira (2015) sinaliza um possível consenso da literatura a respeito da necessidade de superação do modelo tecnicista hegemônico nas licenciaturas. Da mesma forma, concordamos com Nóvoa (2017) quando o autor defende a necessidade de se transformar a formação de professores. As DCN de 2019 parecem não contribuir para uma transformação em direção às ideias defendidas por acadêmicos e entidades do campo. E como poderiam contribuir para a superação de tradições seculares se retomam ideias conservadoras? As transformações advindas pós-golpe parecem afunilar as possibilidades em direção à manutenção de um processo de desprofissionalização da docência.

As formas de materialização dessas diretrizes ainda não são conhecidas. Serão necessários estudos de implementação das novas DCN/2019 para se compreender as interpretações e ações dos formadores frente a elas, bem como suas interações com o processo de implementação das DCN/2015. Com a publicação do Parecer CNE/CP no. 14, de julho de 2020, que dispõe sobre diretrizes próprias para a formação continuada de professores, novos elementos poderão ser incorporados à trajetória da formação docente.

\section{REFERÊNCIAS}

BASTOS, P. Ascensão e crise do governo Dilma Rousseff e o golpe de 2016: poder estrutura, contradição e ideologia. Rev. Econ. Contemp., n. especial, p. 1-63, 2017.

BRASIL. Conselho Nacional de Educação. Parecer CNE/CP 009, de 08 de maio de 2001. Dispõe sobre as Diretrizes para a Formação de Professores da Educação Básica, em nível superior, cursos de licenciatura, de graduação plena. Diário Oficial da União: Seção 1, Brasília, DF, p. 31, 18 abr. 2002.

BRASIL. Conselho Nacional de Educação. Parecer CNE/CP 14, de 10 jul. 2020. Diretrizes Curriculares Nacionais para a Formação Continuada de Professores da Educação Básica e Base Nacional Comum para a Formação Continuada de Professores da Educação Básica. Diário Oficial da União: Seção 1, Brasília, DF, p. 57, 26 out. 2020.

BRASIL. Conselho Nacional de Educação. Parecer CNE/CP 2, de 09 junho de 2015. Diretrizes Curriculares Nacionais para a Formação Inicial e Continuada dos Profissionais do 
Magistério da Educação Básica. Diário Oficial da União: Seção 1, Brasília, DF, p. 13, 25 jun. 2015.

BRASIL. Conselho Nacional de Educação. Parecer CNE/CP 22, de 07 nov. 2019. Diretrizes Curriculares Nacionais para a Formação Inicial de Professores para a Educação Básica e Base Nacional Comum para a Formação Inicial de Professores da Educação Básica. Diário Oficial da União: Seção 1, Brasília, DF, p. 142, 20 dez. 2019.

BRASIL. Conselho Nacional de Educação. Resolução CNE/CES 246, de 04 de maio de 2016. Diretrizes Curriculares Nacionais para a Formação Inicial e Continuada em Nível Superior para Funcionários da Educação Básica. Diário Oficial da União: Seção 1, Brasília, p. 49, DF, 12 maio 2016.

BRASIL. Conselho Nacional de Educação. Resolução CNE/CP 1, de 18 de fevereiro de 2002. Institui Diretrizes Curriculares Nacionais para a Formação de Professores da Educação Básica, em nível superior, curso de licenciatura, de graduação plena. Diário Oficial da União: Seção 1, Brasília, DF, p. 31, 09 abr. 2002.

BRASIL. Conselho Nacional de Educação. Resolução CNE/CP 1, de 9 de agosto de 2017. Altera o Art. 22 da Resolução $\mathrm{CNE} / \mathrm{CP} \mathrm{n}^{\circ}$ 2, de $1^{\circ}$ de 2015. Diário Oficial da União: Seção 1, Brasília, DF, p. 26, 10 ago. 2017.

BRASIL. Conselho Nacional de Educação. Resolução CNE/CP 2, de 1 de julho de 2015. Diretrizes Curriculares Nacionais para a formação inicial em nível superior e formação continuada. Diário Oficial da União: Seção 1, Brasília, DF, p. 8-12, 02 jul. 2015.

BRASIL. Conselho Nacional de Educação. Resolução CNE/CP 2, de 19 de fevereiro de 2002. Institui a duração e a carga horária dos cursos de licenciatura. Diário Oficial da União: Seção 1, Brasília, DF, p. 09, 04 mar. 2002.

BRASIL. Conselho Nacional de Educação. Resolução CNE/CP 2, de 20 de dezembro de 2019. Diretrizes Curriculares Nacionais para a Formação Inicial de Professores para a Educação Básica e Base Nacional Comum para a Formação Inicial de Professores da Educação Básica. Diário Oficial da União: Seção 1, Brasília, DF, p. 46-49, 20 dez. 2019.

BRASIL. Conselho Nacional de Educação. Resolução CNE/CP 2, de 22 de dezembro DE 2017. Institui e orienta a implantação da Base Nacional Comum Curricular da Educação Básica. Diário Oficial da União: Seção 1, Brasília, DF, p. 41-44, 22 dez. 2017.

BRASIL. Conselho Nacional de Educação. Resolução CNE/CP 3, de 3 de outubro de 2018. Altera o Art. 22 da Resolução $\mathrm{CNE} / \mathrm{CP} \mathrm{n}^{\circ}$ 2, de $1^{\circ}$ de 2015. Diário Oficial da União: Seção 1, Brasília, DF, p. 21, 04 out. 2018.

BRASIL. Lei n. 9.394, de 20 de dezembro de 1996. Lei de Diretrizes e Bases da Educação Nacional. Diário Oficial da União: Seção 1, Brasília, DF, n. 248, p. 27833, 23 dez. 1996. PL $1258 / 1988$

COSTA, C. O Tema da Qualidade no Plano Nacional de Educação (2014-2024). 2016. 96 f. Dissertação (Mestrado em Educação) - Programa de Pós-Graduação em Educação, Pontifícia Universidade Católica do Rio de Janeiro, Rio de Janeiro, 2016. 
DINIZ-PEREIRA, J. Formação de professores da Educação Básica no Brasil no limiar dos 20 anos da LDBEN. Notandum, v. 42, p. 139-160, set./dez. 2016.

DINIZ-PEREIRA, J. Formação de professores, trabalho e saberes docentes. Trabalho \& Educação, Belo Horizonte, v. 24, n. 3, p. 143-152, set./dez. 2015.

DOURADO, L. Valorização dos profissionais da educação: desafios para garantir conquistas da democracia. Revista Retratos da Escola, Brasília, v. 10, n. 18, p. 37-56, jan./jun. 2016.

DOURADO, L.; SIQUEIRA, R. A arte do disfarce: BNCC como gestão e regulação do currículo. RBPAE, v. 35, n. 2, p. 291-306, maio/ago. 2019.

FAIRCLOUGH, N. Discurso e mudança social. Brasília: Universidade de Brasília, 2001.

FREITAS, H. Formação de professores no Brasil: 10 anos de embate entre projetos de formação. Educação \& Sociedade, Campinas, v. 23, n. 80, p. 136-167, set. 2002.

GATTI, B. et al. A trajetória das políticas em formação de professores e professoras, em: Professores do Brasil: novos cenários de formação. Brasília: UNESCO, 2019. p. 45-78.

NÓVOA, A. Firmar a posição como professor, afirmar a profissão docente. Cadernos de Pesquisa v. 47, n. 166, p. 1106-1133, out./dez. 2017.

OLIVEIRA, B. R. A implementação de políticas educacionais no nível micro: uma análise a partir dos profissionais da escola no contexto da prática. Revista de Estudios Teóricos y Epistemológicos en Política Educativa, v. 4, p. 1-17, 2019.

OLIVEIRA, B. R. et al. Política de formação de professores nas últimas décadas no Brasil: avanços, desafios, possibilidades e retrocessos. Roteiro, Joaçaba, Edição Especial, p. 47-76, dez. 2018.

ROLDÃO, M. Profissionalidade docente em análise: especificidades docentes do ensino superior e não superior. Nuances: estudos sobre educação, ano XI, v. 12, n. 13, jan./dez. 2005.

SCHEIBE, L.; BAZZO, V. Formação de professores da educação básica no ensino superior: diretrizes curriculares pós 1996. Revista Internacional de Educação Superior, Campinas, v. 2, n. 2, p. 241-256, maio/ago. 2016.

SHIROMA, E.; CAMPOS, R.; GARCIA, R. Decifrar textos para compreender a política: subsídios teórico-metodológicos para análise de documentos. Perspectiva, Florianópolis, v. 23, n. 02, p. 427-446, jul./dez. 2005.

TARDIF, M. Saberes profissionais dos professores e conhecimentos universitários Elementos para uma epistemologia da prática profissional dos professores e suas conseqüências em relação à formação para o magistério. Revista Brasileira de Educação, n. 13, jan./abr. 2000. 


\section{Como referenciar este artigo}

FICHTER FILHO, G. A.; OLIVEIRA, B. R.; COELHO, J. I. F. A trajetória das Diretrizes Curriculares Nacionais para a formação docente no Brasil: uma análise dos textos oficiais. Revista Ibero-Americana de Estudos em Educação, Araraquara, v. 16, n. esp. 1, p. 940956, mar. 2021. e-ISSN: 1982-5587. DOI: https://doi.org/10.21723/riaee.v16iEsp.1.14930

Submissão em: 20/06/2020

Revisões requeridas em: 16/09/2020

Aceito em: 03/11/2020

Publicado em: 01/03/2021 